\title{
Diabetic Patients Develop Greater Intensity of Postoperative Pain than Non-Diabetics after Open Cholecystectomy: A Pilot Study
}

\author{
Rocío Adriana Martínez-Alpuche1,2, Erick Mauricio Brindis-Fuentes², \\ Crystel Guadalupe Guzmán-Priego ${ }^{1}$, Francisco Valenzuela-Priego ${ }^{2}$, \\ Leonor Ivonne Parra-Flores ${ }^{1}$, Jorge Elías Torres-López ${ }^{1,2 *}$
}

\author{
${ }^{1}$ Pain Mechanisms Laboratory, División Académica de Ciencias de la Salud, Universidad Juárez Autónoma de Tabasco, \\ Villahermosa, Tabasco, México \\ ${ }^{2}$ Department of Anaesthesiology, Hospital Regional de Alta Especialidad “Dr. Juan Graham Casasús”, Villahermosa, Tabasco, \\ México \\ Email: *jorge.torres@ujat.mx
}

How to cite this paper: Martínez-Alpuche, R.A., Brindis-Fuentes, E.M., Guzmán-Priego, C.G., Valenzuela-Priego, F., Parra-Flores, L.I. and Torres-López, J.E. (2021) Diabetic Patients Develop Greater Intensity of Postoperative Pain than Non-Diabetics after Open Cholecystectomy: A Pilot Study. Journal of Biosciences and Medicines, 9, 67-75.

https://doi.org/10.4236/jbm.2021.96006

Received: April 21, 2021

Accepted: June 6, 2021

Published: June 9, 2021

Copyright () 2021 by author(s) and Scientific Research Publishing Inc. This work is licensed under the Creative Commons Attribution International License (CC BY 4.0).

http://creativecommons.org/licenses/by/4.0/

\section{(c) (i) Open Access}

\begin{abstract}
Background: Pre-clinical and clinical studies have shown that inflammatory pain intensity is increased under diabetes condition. Open cholecystectomy (OC) is a surgical procedure with predictable postoperative pain. However, the comparison of postoperative pain due to open cholecystectomy in diabetic and non-diabetic patients remains unknown. The research question to answer was whether diabetic patients undergoing OC development greater intensity of postoperative pain than non-diabetic patients. Methods: The study was conducted between June 2016 and February 2018 at the Regional Hospital of High Specialty "Dr. Juan Graham Casasús" of Villahermosa, Tabasco, Mexico. Seventy patients in two groups of 35 patients each scheduled for OC under general anesthesia were studied. Pain was assessed using the 11-point numerical rating scale (NRS). The primary endpoint was to know NRS pain scores after awaking of general anesthesia. Secondary outcomes included the time of onset of pain and comparing NRS scores between diabetic and non-diabetic patients undergoing OC. Results: Diabetic patients reported significantly greater intensity pain than non-diabetic patients. The mean overall pain score in the diabetic and non-diabetic patients was $7.2 \pm 0.3$ and $5.3 \pm 0.3(\mathrm{P}=0.0002)$, respectively. Furthermore, $60 \%$ of diabetic patients had severe pain $(\mathrm{NRS} \geq 8)$ compared to $20 \%$ of non-diabetics $(\mathrm{P}=0.006)$. The time to onset postoperative pain was about 35 minutes in both groups $(\mathrm{P}=$ 0.876). Conclusions: Diabetic patients undergoing OC have greater intensity postoperative pain and also more frequency of patients with severe pain
\end{abstract}


scores compared with non-diabetic patients. Therefore, analgesic treatment in those patients should consider this point in order to provide a satisfactory postoperative analgesia.

\section{Keywords}

Postoperative Pain, Inflammatory Pain, Cholecystectomy, Diabetes, Observational Study

\section{Introduction}

Diabetes is a chronic disease characterized mainly by hyperglycemia and there is experimental evidence that diabetes or hyperglycemia induces peripheral and central sensitization, which translates into greater sensitivity to a painful stimulus (hyperalgesia and allodynia) [1] [2] [3]. Putatively, this sensitization involves both the inflammatory and the neuropathic mechanisms [1] [4] [5]. Also, the analgesic efficacy and potency of different groups of analgesic drugs decrease in diabetic animals [5] [6] [7], and in diabetic patients [8], independently of the route of administration. Likewise, several reports show that diabetic patients report more intensity of postoperative pain after lumbar spine surgery or total abdominal hysterectomy than non-diabetic patients [8] [9]. Overall, the intensity of inflammatory pain or postoperative pain is greater both in experimental models of hyperglycemia or diabetes and in diabetic patients compared to non-diabetics. On the other hand, cholecystectomy is the surgical procedure for treatment symptomatic gallstones, also known as cholelithiasis. To date, laparoscopy cholecystectomy (LC) is the approach of choice for acute cholecystitis and has replaced open cholecystectomy (OC) [10], because LC reduces postoperative morbidity and hospital stay. However, OC is the current treatment of care for others [11]-[16] and OC has been associated with severe postoperative pain [17] [18]. However, the intensity of pain due to cholecystectomy in diabetic patients to date remains unknown. The research question to answer was whether diabetic patients undergoing $\mathrm{OC}$ development higher intensity postoperative pain than non-diabetic patients.

\section{Material and Methods}

This was a prospective, cross-sectional, observational study conducted from June 2016 to February 2018 (ACTRN12618000643279) and was led in accordance with the declaration of Helsinki. Seventy diabetic patients (5 males and 65 females), aged 18 - 65 years undergoing elective open cholecystectomy under general anesthesia were enrolled. The study was conducted at the Regional Hospital of High Specialty "Dr. Juan Graham Casasús” of Villahermosa, Tabasco, Mexico. All patients underwent a preoperative assessment before surgery. Inclusion criteria for this study were age $>18 \mathrm{yr}$, weight $>40 \mathrm{~kg}$, and American Society of Anesthesiology physical status (ASA) I, II or III. Exclusion criteria were defined 
as allergy to non-steroidal anti-inflammatory drugs, history of peptic ulcer disease, hemorrhagic diathesis, coronary heart disease, bronchial asthma, seizure disorders, pregnancy or any other contraindications.

Data from variables such as age, height, weight, BMI, glucose concentration, duration of surgery, time to onset postoperative pain were obtained from nursing records and the study data sheet. These data were collected by a researcher blinded to the study.

All patients received general anesthesia with standard monitoring. In brief, anesthesia was induced with propofol $2-3 \mathrm{mg} / \mathrm{kg}$ and fentanyl $5 \mu \mathrm{g} / \mathrm{kg}$. Tracheal intubation was facilitated by vecuronium $0.1 \mathrm{mg} / \mathrm{kg}$. Anesthesia was maintained with sevoflurane $1.5 \%$ and fentanyl $5 \mu \mathrm{g} / \mathrm{kg}$. Patients also received diclofenac $75 \mathrm{mg}$ i.v. once before the surgical incision. At the end of surgery, neuromuscular blockade was reversed with neostigmine $0.03 \mathrm{mg} / \mathrm{kg}$ and atropine $0.1 \mathrm{mg} / \mathrm{kg}$. A continuous infusion of $0.9 \%$ saline was given at the rate of $5-8 \mathrm{ml} / \mathrm{kg}$ during surgery.

Hemodynamic variables were collected by chart review defined as hypotension (MAP $<60 \mathrm{mmHg}$ ), hypertension (MAP > $100 \mathrm{mmHg}$ ), bradycardia (heart rate $<40$ beats $/ \mathrm{min}$ ) and tachycardia (heart rate $>90$ beats $/ \mathrm{min}$ ) as well as blood glucose concentration. After completion of the surgical procedure (final suture) and emergence from anesthesia, patients were transferred to the recovery room. Duration of surgery was taken from the time of skin incision to completion of skin suturing. Onset of postoperative pain was defined as the time from end of anesthesia until presence of any postoperative pain score. Postoperative pain intensity was assessed by using a $0-10$ numerical rating scale (NRS) $(0=$ no pain and $10=$ worst pain imaginable) and were categorized in "no or mild pain" with NRS $\leq 3$ and NRS $>3$ corresponding to "moderate to severe" pain [19]. Postoperative pain management was carried out immediately after assessment according to institutional standards. Briefly, analgesic drugs that are routinely used for this type of surgery (diclofenac, $75 \mathrm{mg}$ i.v.) or ketorolac (30 mg i.v.) were randomly administered.

\section{Statistical Analysis}

Data for continuous variables (age, height, weight, BMI, glucose concentration, duration of surgery, time to onset postoperative pain and NRS values) were analyzed using the Student $t$ test for independent samples, as appropriate to determine between-group differences. About categorical data (sex, ASA, pain intensity), differences between two groups were analyzed using Chi-square test or Fisher exact test as required. All data are presented as means \pm S.E.M. and categorical data are presented as number and frequencies (percentages). $P$-value $<$ 0.05 was considered statistically significant. Data were recorded in and analyzed using GraphPad Prism 9.1.0 Software (San Diego, California, USA).

\section{Results}

Seventy patients who underwent open cholecystectomy were studied in two 
groups of 35 patients each (Table 1). The two groups were comparable regarding sex, height, weight, BMI, but not ASA status (Table 1). Diabetic patients were significantly older than non-diabetic patients (Table 1). The mean duration of surgery in diabetic group was 81.7 minutes and in the non-diabetic group was 70.8 minutes, without difference between two groups (Table 1). Onset of postoperative pain was similar in both groups with about 35 minutes (Table 2).

Diabetic patients undergoing open cholecystectomy reported significantly higher pain intensity than non-diabetic patients. Regarding pain intensity, the results of this research show a lower frequency of diabetic patients with moderate pain. In contrast, diabetes patients (about 60\%) reported severe pain compared to non-diabetics (about 20\%) with severe pain (Table 2). Statistical analysis revealed difference between groups (Table 2). The intensity of postoperative pain measured with the NRS is shown in Figure 1. The mean overall pain score in the diabetic and non-diabetic patients was $7.1 \pm 0.3$ (severe) and $5.6 \pm 0.3$ (moderate), respectively (Figure 1).

\section{Discussion}

The present study was designed with the primary aim of examining acute

Table 1. Patient characteristics and physical status.

\begin{tabular}{cccc}
\hline & $\begin{array}{c}\text { Diabetic patients } \\
(\mathbf{n}=\mathbf{3 5})\end{array}$ & $\begin{array}{c}\text { Non-diabetic patients } \\
(\mathbf{n}=\mathbf{3 5})\end{array}$ & $\boldsymbol{p}$ \\
\hline Sex (Male/Female) & $3 / 32$ & $2 / 33$ & 0.643 \\
Age (yr) & $65.6 \pm 2.6$ & $35.6 \pm 2.3$ & 0.001 \\
BMI & $29.2 \pm 0.7$ & $29.0 \pm 0.8$ & 0.876 \\
ASA (I/II/III) & $0 / 29 / 6$ & $21 / 13 / 1$ & 0.001 \\
Heart rate (beats/min) & $80.5 \pm 1.9$ & $76.1 \pm 2.1$ & 0.123 \\
MAP (mmHg) & $95.3 \pm 1.7$ & $93.3 \pm 1.7$ & 0.424 \\
Glucose (mg/dL) & $165.4 \pm 10.6$ & $95.0 \pm 2.3$ & 0.001 \\
Duration of surgery (min) & $81.7 \pm 4.2$ & $70.8 \pm 6.3$ & 0.158 \\
\hline
\end{tabular}

BMI; Body Mass Index. MAP; Mean Arterial Pressure. Values are expressed as mean \pm standard error.

Table 2. Onset and postoperative pain intensity in diabetic and non-diabetic patients undergoing open cholecystectomy.

\begin{tabular}{cccc}
\hline & $\begin{array}{c}\text { Diabetic patients } \\
\mathbf{n}=35\end{array}$ & $\begin{array}{c}\text { Non-diabetic patients } \\
\mathbf{n}=35\end{array}$ & $p$ \\
\hline Onset of postoperative pain (min) & $34.4 \pm 5.2^{*}$ & $35.4 \pm 3.3^{\star}$ & 0.876 \\
Postoperative pain intensity (NRS) & $\mathrm{n}(\%)$ & $\mathrm{n}(\%)$ & 0.006 \\
Mild $(1-3)$ & $3(8.6)$ & $5(14.3)$ & $23(65.7)$ \\
Moderate $(4-7)$ & $12(34.3)$ & $7(20.0)$ & \\
Severe $(8-10)$ & $20(57.1)$ & & \\
\hline
\end{tabular}

${ }^{\star}$ Values are expressed as mean \pm standard error. 


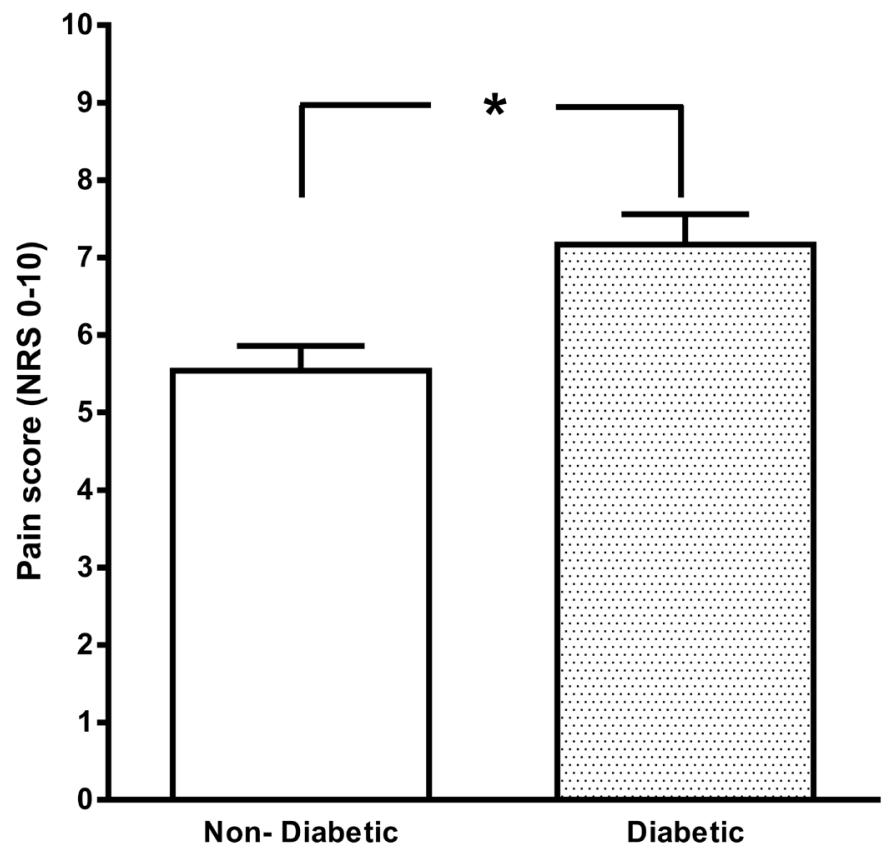

Figure 1. Comparison of pain scores between non-diabetic and diabetic patients undergoing open cholecystectomy. Data are the mean \pm S.E.M. for 35 patients in each group. ${ }^{\star}$ Differences between the groups were determined using Student t-test, $\mathrm{p}<0.05$.

postoperative pain intensity of diabetic patients after OC. Importantly, the findings of this study indicate that diabetic patients undergoing OC report having higher intensity postoperative pain compared to non-diabetic patients. The results of this research observed in non-diabetic patients agree with those described by other investigations that evaluated postoperative pain after open cholecystectomy. In this sense, demographic data and duration of surgery (about 80 min) and pain intensity was moderate to severe upon arrival to the recovery room or time zero [11] [12] [13] [20] [21] or $0.5-1 \mathrm{~h}$ later [14] [15]. About onset time of pain was about 35 minutes, this data was similar to about 40 minutes previously reported by others, for patients undergoing open cholecystectomy [16]. Interesting, in the present study, the onset of pain in diabetic and non-diabetic patients was similar, it could suggest that the development of postoperative pain, does not depend on the diabetic condition.

On the other hand, pain severity and the proportion of patients with mild, moderate or severe pain, it was diabetic patients who had the highest proportion with scores corresponding to severe pain. Patients with diabetes were older than non-diabetic patients (65 years vs 35 years), so it cannot be ruled out that they had peripheral neuropathy which is common in people with diabetes [22]. and that this could be associated with worsening postoperative pain. Additional to latter, data such as age may have an effect on intensity of postsurgical pain [17]. Our results are in line with those of Karci and co-workers 2004 [8], in which diabetic patients undergoing abdominal hysterectomy reported higher pain scores and also more patients required rescue analgesic than non-diabetic patients. Similarly, diabetic patients with knee osteoarthritis compared with non-diabetics 
have higher pain intensity [23]. Also, the pain threshold measured in the oral mucosa, the tips of the fingers and toes was lower in diabetic than non-diabetic patients [24]. Furthermore, diabetic patients with glycosylated hemoglobin (HbA1c) greater than $6.5 \%$ have more incidence of inadequate analgesia in the early postoperative period [25] or higher analgesic requirements in the intraoperative period [26], suggesting that those patients have higher pain scores than non-diabetic patients with $\mathrm{HbAlc}$ less than 6.5\%. Taken together, it can be assumed that for diabetic patients, pain reduction may decrease with uncontrolled diabetes determined by high HbAlc values [27].

It is known that non-diabetic patients with open cholecystectomy show moderate to severe postoperative pain [28] [29]. In this sense, Polanco-García et al., (2017) have shown that mean score pain after general surgery was about to 6 NRS (severe pain) and percentage of patients was about 40\% [30]. Although, non-diabetic and diabetic patients reported moderate to severe postoperative pain, the incidence of severe postoperative pain was higher diabetic patients. The results of present study and other clinical studies [23] suggest that diabetes increases surgery-induced painful hypersensitivity, similarly, as described in several preclinical studies [1] [3]. Postoperative pain is associated with tissue injury due to the surgical procedure. Tissue damage typically produces persistent pain and hyperalgesia. Mounting evidence indicates that persistent pain and hyperalgesia result from peripheral and central sensitization. All these mechanisms contribute to the post-injury pain hypersensitivity state. Experimental models of tissue injury have shown that diabetic animals develop more hyperalgesia as compared with non-diabetic animals [1] [2] [4] [5]. The mechanisms that lead to this hypersensitivity in diabetic animals are not total clear. However, it has been proposed that peripheral and central mechanisms participate in this process. There is evidence for the participation of spinal cyclooxygenase 2 (COX-2), cholecystokinin (CCK) receptors and $\mathrm{K}^{+}-\mathrm{Cl}^{-}$co-transporter 2 (KCC2), among others, in hypersensitivity-induced diabetes [1] [2] [31] [32]. There is consensus that a better understanding of acute pain after surgery is needed, and that there are risk factors that contribute to the severity of postoperative pain, including the patient's preexisting pain [33] such painful diabetic neuropathies. The results of the present study suggest that diabetic patients show a pain hypersensitivity, which can further increase surgical procedure-induced pain. Thus, diabetic patients should be considered as a special population regarding postoperative pain. Analgesic treatment in those patients should consider this point in order to provide a satisfactory postoperative analgesia.

Our study has the following limitations. First, included lack of randomized allocation of patients to the two groups. Second, pain assessment was limited to the evaluation of onset pain after arriving to recovery room only, so the time course of pain was not evaluated. Third, because of the observational nature of the study, no particular postoperative analgesic treatment was proposed, were administered analgesic drugs that are routinely used for this type of surgery 
(diclofenac or ketorolac). Therefore, rescue analgesia was not evaluated.

\section{Acknowledgements}

This work was partially supported by Universidad Juárez Autónoma de Tabasco UJAT), grant OP/PROFOCIE-2014-27MSV0018V-07-02.

\section{Conflicts of Interest}

The authors declare no conflicts of interest regarding the publication of this paper.

\section{References}

[1] Juárez-Rojop, I.E., Granados-Soto, V., Díaz-Zagoya, J.C., Flores-Murrieta, F.J. and Torres-López, J.E. (2006) Involvement of Cholecystokinin in Peripheral Nociceptive Sensitization during Diabetes in Rats as Revealed by the Formalin Response. Pain, 122, 118-125. https://doi.org/10.1016/j.pain.2006.01.018

[2] Ramos, K.M., Jiang, Y., Svensson, C.I. and Calcutt, N.A. (2007) Pathogenesis of Spinally Mediated Hyperalgesia in Diabetes. Diabetes, 56, 1569-1576. https://doi.org/10.2337/db06-1269

[3] Ismail, C.A.N., Suppian, R., Aziz, C.B.A., Haris, K. and Long, I. (2019) Increased Nociceptive Responses in Streptozotocin-Induced Diabetic Rats and the Related Expression of Spinal NR2B Subunit of N-Methyl-D-Aspartate Receptors. Diabetes \& Metabolism Journal, 43, 222-235. https://doi.org/10.4093/dmj.2018.0020

[4] Freshwater, J.D., Svensson, C.I., Malmberg, A.B. and Calcutt, N.A. (2002) Elevated Spinal Cyclooxygenase and Prostaglandin Release during Hyperalgesia in Diabetic Rats. Diabetes, 51, 2249-2255. https://doi.org/10.2337/diabetes.51.7.2249

[5] Torres-López, J.E., Juárez-Rojop, I.E., Granados-Soto, V., Granados-Soto, V., Flores-Murrieta, F.J., Flores-Murrieta, F.J., et al. (2007) Peripheral Participation of Cholecystokinin in the Morphine-Induced Peripheral Antinociceptive Effect in Non-Diabetic and Diabetic Rats. Neuropharmacology, 52, 788-795. https://doi.org/10.1016/j.neuropharm.2006.09.015

[6] Shaqura, M., Khalefa, B.I., Shakibaei, M., Winkler, J., Al-Khrasani, M., Fürst, S., et al. (2013) Reduced Number, G Protein Coupling, and Antinociceptive Efficacy of Spinal Mu-Opioid Receptors in Diabetic Rats Are Reversed by Nerve Growth Factor. Journal of Pain, 14, 720-730. https://doi.org/10.1016/j.jpain.2013.01.776

[7] Balogh, M., Zádor, F., Zádori, Z.S., Shaqura, M., Király, K., Mohammadzadeh, A., et al. (2019) Efficacy-Based Perspective to Overcome Reduced Opioid Analgesia of Advanced Painful Diabetic Neuropathy in Rats. Frontiers in Pharmacology, 10, Article No. 347. https://doi.org/10.3389/fphar.2019.00347

[8] Karci, A., Tasdogen, A., Erkin, Y., Aktaş, G. and Elar, Z. (2004) The Analgesic Effect of Morphine on Postoperative Pain in Diabetic Patients. Acta Anaesthesiologica Scandinavica, 48, 619-624. https://doi.org/10.1111/j.1399-6576.2004.00387.x

[9] Takahashi, S., Suzuki, A., Toyoda, H., Terai, H., Dohzono, S., Yamada, K., et al. (2013) Characteristics of Diabetes Associated with Poor Improvements in Clinical Outcomes after Lumbar Spine Surgery. Spine, 38, 516-522.

https://doi.org/10.1097/BRS.0b013e318273583a

[10] Mou, D., Tesfasilassie, T., Hirji, S. and Ashley, S.W. (2019) Advances in the Management of Acute Cholecystitis. Annals of Gastroenterological Surgery, 3, 247-253. https://doi.org/10.1002/ags3.12240 
[11] Bahar, M.M., Jangjoo, A., Soltani, E., Armand, M. and Mozaffari, S. (2010) Effect of Preoperative Rectal Indomethacin on Postoperative Pain Reduction after Open Cholecystectomy. Journal of PeriAnesthesia Nursing, 25, 7-10. https://doi.org/10.1016/j.jopan.2009.11.002

[12] Safavi, M., Honarmand, A. and Nematollahy, Z. (2011) Pre-Incisional Analgesia with Intravenous or Subcutaneous Infiltration of Ketamine Reduces Postoperative Pain in Patients after Open Cholecystectomy: A Randomized, Double-Blind, Placebo-Controlled Study. Pain Medicine, 12 1418-1426. https://doi.org/10.1111/j.1526-4637.2011.01205.x

[13] Bharti, N., Dontukurthy, S, Bala, I. and Singh, G. (2013) Postoperative Analgesic Effect of Intravenous (i.v.) Clonidine Compared with Clonidine Administration in Wound Infiltration for Open Cholecystectomy. British Journal of Anaesthesia, 111, 656-661. https://doi.org/10.1093/bja/aet130

[14] Kuju, R.B., Dongol, Y. and Verma, R. (2016) Effectiveness of Spinal Anaesthesia versus General Anaesthesia for Open Cholecystectomy. Journal of Nepal Health Research Council, 14, 93-98.

[15] Fentie, D.Y., Gebremedhn, E.G., Denu, Z.A. and Gebreegzi, A.H. (2017) Efficacy of Single-Injection Unilateral Thoracic Paravertebral Block for Post Open Cholecystectomy Pain Relief: A Prospective Randomized Study at Gondar University Hospital. Local and Regional Anesthesia, 10, 67-74.

https://doi.org/10.2147/LRA.S133946

[16] Mottaghi, K., Safari, F., Sezari, P., Salimi, A. and Nashibi, M. (2019) Effect of Intrapleural Meperidine on Post-Operative Pain after Open Cholecystectomy. Tanaffos, 18, 79-83.

[17] Garimella, V. and Cellini, C. (2013) Postoperative Pain Control. Clinics in Colon and Rectal Surgery, 26, 191-196. https://doi.org/10.1055/s-0033-1351138

[18] Gerbershagen, H.J., Aduckathil, S., van Wijck, A.J.M., Peelen, L.M., Kalkman, C.J. and Meissner, W. (2013) Pain Intensity on the First Day after Surgery: A Prospective Cohort Study Comparing 179 Surgical Procedures. Anesthesiology, 118, 934-944. https://doi.org/10.1097/ALN.0b013e31828866b3

[19] Ledowski, T., Tiong, W.S., Lee, C., Wong, B., Fiori, T. and Parker, N. (2013) Analgesia Nociception Index: Evaluation as a New Parameter for Acute Postoperative Pain. British Journal of Anaesthesia, 111, 627-629.

https://doi.org/10.1093/bja/aet111

[20] Bahar, M., Rosen, M. and Vickers, M.D. (1985) Self-Administered Nalbuphine, Morphine and Pethidine: Comparison, by Intravenous Route, Following Cholecystectomy. Anaesthesia, 40, 529-532.

https://doi.org/10.1111/j.1365-2044.1985.tb10888.x

[21] Bhatia, A., Kashyap, L., Pawar, D.K. and Pawar, D.K. (2004) Effect of Intraoperative Magnesium Infusion on Perioperative Analgesia in Open Cholecystectomy. Journal of Clinical Anesthesia, 16, 262-265. https://doi.org/10.1016/j.jclinane.2003.08.012

[22] Barrell, K. and Smith, A.G. (2019) Peripheral Neuropathy. Medical Clinics of North America, 103, 383-397. https://doi.org/10.1016/j.mcna.2018.10.006

[23] Eitner, A., Pester, J., Vogel, F., Marintschev, I., Lehmann, T., Hofmann, G.O., et al. (2017) Pain Sensation in Human Osteoarthritic Knee Joints Is Strongly Enhanced by Diabetes Mellitus. Pain, 158, 1743-1753. https://doi.org/10.1097/j.pain.0000000000000972

[24] Ogawa, T., Kimoto, S., Nakashima, Y., Furuse, N., Ono, M., Furokawa, S., et al. (2018) Differences in Pain Thresholds Elicited by Intraoral Electrical Stimuli be- 
tween Individuals with and without Diabetes Mellitus. Journal of Oral Rehabilitation, 45, 235-239. https://doi.org/10.1111/joor.12601

[25] Kim, S.H. and Hwang, J.H. (2015) Preoperative Glycosylated Haemoglobin as a Predictor of Postoperative Analgesic Requirements in Diabetic Patients: A Prospective Observational Study. European Journal of Anaesthesiology, 32, 705-711. https://doi.org/10.1097/EJA.0000000000000282

[26] Cheisson, G., Jacqueminet, S., Cosson, E., Ichai, C., Leguerrier, A.-M., Nicolescu-Catargi, B., et al. (2018) Perioperative Management of Adult Diabetic Patients. Intraoperative Period. Anaesthesia Critical Care \& Pain Medicine, 37, S21-S25. https://doi.org/10.1016/j.accpm.2018.02.018

[27] Wong, F., Namdari, B., Dupler, S., Kovac, M.F., Makarova, N., Dalton, J.E., et al. (2016) No Difference in Pain Reduction after Epidural Steroid Injections in Diabetic versus Nondiabetic Patients: A Retrospective Cohort Study. Journal of Anaesthesiology Clinical Pharmacology, 32, 84-88. https://doi.org/10.4103/0970-9185.173334

[28] Kaur, S., Saroa, R. and Aggarwal, S. (2015) Effect of Intraoperative Infusion of Low-Dose Ketamine on Management of Postoperative Analgesia. Journal of Natural Science, Biology and Medicine, 6, 378-382. https://doi.org/10.4103/0976-9668.160012

[29] Keus, F., de Jong, J., Gooszen, H.G. and Laarhoven, C.J. (2006) Laparoscopic versus Open Cholecystectomy for Patients with Symptomatic Cholecystolithiasis. Cochrane Database of Systematic Reviews, No. 4, Article No. CD006231. https://doi.org/10.1002/14651858.CD006231

[30] Polanco-García, M., García-Lopez, J., Fàbregas, N., Meissner, W. and Puig, M.M. (2017) Postoperative Pain Management in Spanish Hospitals: A Cohort Study Using the PAIN-OUT Registry. Journal of Pain, 18, 1237-1252. https://doi.org/10.1016/j.jpain.2017.05.006

[31] Jolivalt, C.G., Lee, C.A., Ramos, K.M. and Calcutt, N.A. (2008) Allodynia and Hyperalgesia in Diabetic Rats Are Mediated by GABA and Depletion of Spinal Potassium-Chloride Co-Transporters. Pain, 140, 48-57. https://doi.org/10.1016/j.pain.2008.07.005

[32] Roa-Coria, J.E., Pineda-Farias, J.B., Barragán-Iglesias, P., Quiñonez-Bastidas, G.N., Zúñiga-Romero, Á., Huerta-Cruz, J.C., et al. (2019) Possible Involvement of Peripheral TRP Channels in the Hydrogen Sulfide-Induced Hyperalgesia in Diabetic Rats. BMC Neuroscience, 20, Article No. 1. https://doi.org/10.1186/s12868-018-0483-3

[33] Eisenach, J.C. and Brennan, T.J. (2018) Pain after Surgery. Pain, 159, 1010-1011. https://doi.org/10.1097/j.pain.0000000000001223 